\title{
Chapter 12 \\ Multi-taxa Surveys: Integrating Ecosystem Processes and User Demands
}

\author{
William E. Magnusson, Ben Lawson, Fabricio Baccaro, Carolina Volkmer \\ de Castilho, J. Guy Castley, Flavia Costa, Debora P. Drucker, Elizabeth \\ Franklin, Albertina P. Lima, Regina Luizão, Fernando Mendonça, Flávia \\ Pezzini, Juliana Schietti, José Julio Toledo, Ana Tourinho, Luciano M. \\ Verdade and Jean-Marc Hero
}

\begin{abstract}
Globally, natural resource management agencies are increasingly recognizing the importance of long-term ecological research (LTER) for monitoring biodiversity, ranging from relatively simple, known, local-level issues, such as managing tourist impacts in a conservation park, to more complex, multifaceted, pervasive, and far-reaching impacts, such as global climate change. Much previous literature has confused protocols for LTER projects to answer current research questions, with developing a system for long-term ecological monitoring. Contrary to perceptions that these LTER systems are not driven by well-defined objectives, we argue that LTER systems can be designed and implemented with the specific objective of providing a basis for both LTER projects and long-term monitoring. We present an overview of RAPELD,
\end{abstract}

\footnotetext{
W. E. Magnusson ( $\varangle)$ - F. Baccaro - F. Costa - E. Franklin - A. P. Lima - R. Luizão F. Pezzini - J. Schietti - J. J. Toledo - A. Tourinho Instituto Nacional de Pesquisas da Amazonia (INPA), Caixa Postal 478, Manaus, AM 69011-970, Brazil e-mail: bill@inpa.gov.br

F. Baccaro

e-mail: fabricera@gmail.com

F. Costa

e-mail: flaviacosta001 @gmail.com

E. Franklin

e-mail: beth@inpa.gov.br

A. P. Lima

e-mail: lima@inpa.gov.br

R. Luizão

e-mail: rcel@inpa.gov.br

F. Pezzini

e-mail: flaviapezini@gmail.com

J. Schietti

e-mail: jujuschietti@gmail.com
} 
an LTER system developed in Brazil, with comparable infrastructure established in Australia and Nepal. The standardized biodiversity infrastructure and research platform provides a long-term basis for powerful multi-disciplinary, multi-scale analyses.

\subsection{Introduction}

In 2002, the US Secretary of Defense, Donald Rumsfeld, used the phrase "unknown unknowns" to describe critically important aspects of military defense that are essentially unpredictable until they start to have an effect. Taleb (2007) more generally used the term "black swans" to describe rare and unpredictable phenomena that have a disproportionate effect on human lives, but focused on economic aspects. In the context of biodiversity conservation and management, such black swans include unpredictable long-term global issues, such as climate change (Doak et al. 2008; Wintle et al. 2010).

J. J. Toledo

e-mail: juliotoledo@gmail.com

A. Tourinho

e-mail: amtourinho@gmail.com

B. Lawson - J. Guy Castley - J.-M. Hero

Environmental Futures Centre, School of Environment, Griffith University,

Gold Coast Campus, Gold Coast, QLD 4222, Australia

e-mail: zzbenlaw@uqconnect.net

J. Guy Castley

e-mail: g.castley@griffith.edu.au

J.-M Hero

e-mail: m.hero@griffith.edu.au

C. V. de Castilho

Centro de Pesquisa Agroflorestal de Roraima, Empresa Brasileira de Pesquisa Agropecuária (EMBRAPA), BR 174, Km 8, Distrito Industrial, Boa Vista, RR 69301-970, Brazil

e-mail: carolina@cpafrr.embrapa.br

D. P. Drucker

EMBRAPA Monitoramento por Satélite, Av. Soldado Passarinho, 303, Campinas,

SP 13070-115, Brazil

e-mail: debora@enpm.embrapa.br

F. Mendonça

Instituto de Saúde e Biotecnologia—ISB, Universidade Federal do Amazonas-UFAM,

Campus Universitário do Médio Solimões, Estrada Coari-Mamiá, 305, Coari,

AM 69460-000, Brazil

e-mail: femandopmendonca@gmail.com

L. M. Verdade

Centro de Energia Nuclear na Agricultura, Universidade de São Paulo, Caixa Postal 96,

Piracicaba, SP 13416-000, Brazil

e-mail: Imverdade@usp.br 
The black swan concept goes to the heart of a long-running debate about the value of long-term ecological monitoring and whether the approaches advocated by various authors are able to achieve their stated objectives (Magnusson et al. 2005, 2008; Ferraz et al. 2008; Lindenmayer and Likens 2009; Haughland et al. 2010). Much of this debate we feel can be attributed to a misunderstanding of the fundamental differences between designing a long-term ecological research (LTER) project focused on particular questions (Lindenmayer and Likens 2009), and designing an LTER system for addressing current management questions, but which can also detect "black swans" over much greater timescales (Magnusson et al. 2005; Haughland et al. 2010; Costa and Magnusson 2010; Hero et al. 2010).

Designing a monitoring program can benefit from the attention paid to a limited range of management goals, resulting in narrowly focused scientific research projects. This approach works well if all stakeholders are convinced of the relevance of those goals, and it is reasonable to assume that other stakeholders, or goals, will not be forced onto the study. However, these assumptions are likely to apply only to geographically and temporally limited studies.

The LTER project approach to scientific analysis is well suited to monitoring, which has the objective of estimating parameters for pre-established models. However, it is increasingly becoming evident that, without modification, this approach cannot prepare us for early detection of black swans, which are generally unpredicted because our models, rather than the parameter estimates, are badly specified.

Firstly, the cost of implementing an optimal experimental design for each and every known environmental threat within a particular scientific researcher's universe of interest is beyond any reasonable expectation for financing within the foreseeable future (Field et al. 2005). Secondly, even if it were possible to finance such complex experimental designs, these studies would not self-organize into a system that would optimize our chances of detecting and dealing with black swans (Wintle et al. 2010). We argue that developing LTER systems to effectively understand and manage biodiversity requires a paradigm shift in LTER approaches.

In this chapter, we present some outcomes from the RAPELD system for use in LTER networks - a system designed to answer specific research questions in a long-term monitoring framework. It was designed for detecting long-term trends in biodiversity across longitudinal and latitudinal gradients at a global scale and to maximize the chances of detecting black swans. It does this by implementing infrastructure that is useful to a wide range of stakeholders with different objectives and scales of interest, while maintaining the flexibility to deal with specific threats and evolving research questions.

To be of greatest use to the widest range of stakeholders, the RAPELD LTER system was designed around the following eight fundamental requirements:

1. Be technically and spatially standardized.

2. Permit standardized surveys of all taxa.

3. Be large enough to permit survey of all taxa and ecosystem processes.

4. Be modular to permit surveys over large areas. 
5. Be compatible with preexisting initiatives.

6. Can be implemented with available human and monetary resources.

7. Provide data to stakeholders in a reasonable time.

8. Be compatible and integrated with large-scale remote sensing capabilities.

Where possible, surveys should result in abundance estimates, or at least permit evaluation of detectability biases (see Chaps. 9 and 10). Details behind the logic and descriptions of implementation for each of these can be found in Costa and Magnusson (2010), Hero et al. (2010), and the PPBio Web site (http://ppbio.inpa.gov.br). However, even without the details, it should be clear why principles such as these are necessary to attend to the demands of the wide range of biodiversity stakeholders, and a number Westoby 1991; Parr raised by others committed to establishing monitoring networks Gardner 2010). Stakeholders providing manpower, maintaining field to the system in a variety of ways, including niques, providing access to their lands, identifying , developing remote sensing techtory analyses. It is their system.

Biodiversity monitoring represents an extreme case in which the stakeholders, objectives, and funding opportunities are spatially and temporally scale dependent, and there is no overarching institutional framework to coordinate monitorBiodiversity Research illustrate this with examples from the Brazilian Program for methodology. We do not purpo, and the use of RAPELD (Magnusson et al. 2005) in global ecosystems bur to describe the myriad of ecological interactions different stakeholders to make use the RAPELD system allows sometimes changing objectives.

\subsection{How to Catch a Black Swan}

Here, we present some examples of the use of RAPELD infrastructure that provide evidence that LTER systems are much better equipped for detecting black swans. These examples are not exhaustive, but they demonstrate the ability to detect black swans using a well-designed LTER system that provides infrastructure and a framework for answering unexpected multi-scale and multi-disciplinary ecological questions.

1. Reserva Ducke is one of the most accessible and intensively studied field sites in the Neotropics (Pitman et al. 2011), and millions of dollars had been spent in trying to document the biodiversity in the reserve (e.g., Adis 2002; Ribeiro et al. 1999). However, many new species for Reserva Ducke were disand plots) to systematically survey the with infrastructure (permanent trails 2008), plants (Costa et al. 2008, 2009), entire reserve, including birds (Cintra (Menin et al. 2008a, b). One of the most unexpectença et al. 2008), and frogs spumarius, which belongs to one of the most extinction-prone gener 
occurs only in the western drainage of the reserve where the water is slightly less acid (Menin et al. 2008a). That important species had not been detected in the reserve despite many long-term studies undertaken before the field infrastructure was established (e.g., Magnusson et al. 1999; Hero et al. 2001).

Earlier studies, although carried out by experts, had failed to detect many relatively large vascular plants and vertebrates of Reserva Ducke, and these results were replicated in other areas. A graduate student, in a survey of a standard RAPELD grid in the area of influence of the Balbina hydroelectric dam, encountered 58 species of frogs, whereas much more extensive studies by specialists in a much greater area, including more obviously distinct habitats, had revealed only 48 species (Condrati 2009). RAPELD methodology, using relatively inexperienced observers, encountered about twice as many species of amphibians for the same field effort as directed surveys by specialists elaborating environmental impact statements (Goralewski 2008). Apparently, the advantages of systematic sampling far outweigh the advantages of using experts without the benefit of standardized field infrastructure.

2. The existence of long-term ecological research sites using shared infrastructure allows multi-disciplinary studies that were not expected or designed and allow better interpretation of short-term studies using the same methodology. For instance, Dias et al. (2010) used data from an LTER site that also used RAPELD methodology to evaluate the probable effect of seasonality revealed by a short-term study of effects of logging on fish.

3. Remote Sensing: Using standard infrastructure systematically distributed across the landscape facilitates integrating remote sensing with ground truthing. The possibilities for feedbacks between remote sensing and biodiversity surveys can be illustrated with two examples from Amazonian RAPELD sites. Use of Shuttle Radar Topography Mission (SRTM) images is now one of the most useful and robust methods to produce topographic maps over large areas. However, SRTM reflects off forest canopies and may be affected by surface water, and it was not clear how accurate data derived from SRTM was for estimation of altitude over small areas. Schietti et al. (2007) used data from several RAPELD LTER sites to calibrate SRTM data revealing altitudinal precision errors under the canopy over scales of tens of $\mathrm{km}\left(r^{2}=0.7\right)$ with further bias over waterlogged ground. The ability to undertake these calibration measures was fortuitous as the elevation data collected from the LTER plots were not measured with this objective in mind. Nonetheless, these data are proving useful to both remote sensing modelers and biodiversity specialists.

Light detection and ranging (LIDAR) methods use point height data to produce surface topographical strata and can be used to generate structural images of forest canopies. It may therefore be possible to calibrate LIDAR data to estimate arboreal biomass (Lefsky et al. 2002). This has become the objective of a consortium of Brazilian and North American researchers (http://www.amazonpir e.org/) who are using data from RAPELD and other long-term monitoring sites 
in Amazonia to calibrate airborne LIDAR. These data are also being calibrated against ground-based LIDAR and in the future will be used to calibrate satellite LIDAR (M. A. Lefsky, pers. comm.). This is another example preparing for a black swan, in which LIDAR technology was not envisioned when the RAPELD grids were being installed, though the calibration would not have been as effective if remote sensing in general had not been taken into account in designing the RAPELD system (Costa and Magnusson 2010).

4. Many studies have shown biomass accumulation in Amazonian forests. However, only studies undertaken using RAPELD infrastructure have been able to show within-site variation in biomass accumulation due to soils, and short-term (2-year) variation in soil-biomass accumulation relationships (Castilho et al. 2006, 2010). This biomass comparison can be linked to climate change, and data are now comparable with other RAPELD LTER sites nationally and internationally. Although the total biomass per hectare is much greater in the Amazonian rainforest site, the proportion of biomass in each 10-cm-diameter-at-breast-height size class is very similar in Australian eucalypt forest (Fig. 12.1). The proportion of biomass in each size at Reserva Ducke (Castilho et al. 2006) predicts $95 \%$ of the variation between size classes in Karawatha measured by Butler (2007), a result totally unexpected before the comparison was made.

\subsubsection{Examples of LTER Projects that Used RAPELD Infrastructure}

RAPELD LTER infrastructure has proven useful for studies of carbon stocks (Castilho et al. 2006, 2010), decomposition processes (Braga-Neto et al. 2008; Toledo et al. 2009, 2011, 2012), and distributions of plants (Costa et al. 2005, 2009; Kinupp and Magnusson 2005; Drucker et al. 2008), fish (Mendonça et al. 2005; Pazin et al. 2006; Espírito-Santo et al. 2009), amphibians (Menin et al. 2007, 2008b), mammals (Mendes Pontes et al. 2008, 2012; Calzada et al. 2008), and invertebrates (Oliveira et al. 2009; Rodrigues et al. 2010). It has revealed gaps in our knowledge with regard to the effects of forestry (Castilho et al. 2006; Dias et al. 2010) and legislation to protect riparian areas (Drucker et al. 2008; Bueno et al. 2012). It is allowing integration of LTER and ILTER sites in ways that were not previously possible. This is not because RAPELD infrastructure is necessarily optimal for surveys of any particular taxon or ecosystem process. Its strength comes from planning which encourages interactions among researchers from diverse fields as well as with management and industry partners. It would appear that the usefulness of the infrastructure provided by the RAPELD system is more limited by our imagination than by any limits in the design. 
Fig. 12.1 Proportion of biomass in 10-cm-diameterat-breast-height size classes of trees in Reserva Ducke, Amazonas, Brazil, and Karawatha Reserve, Queensland, Australia
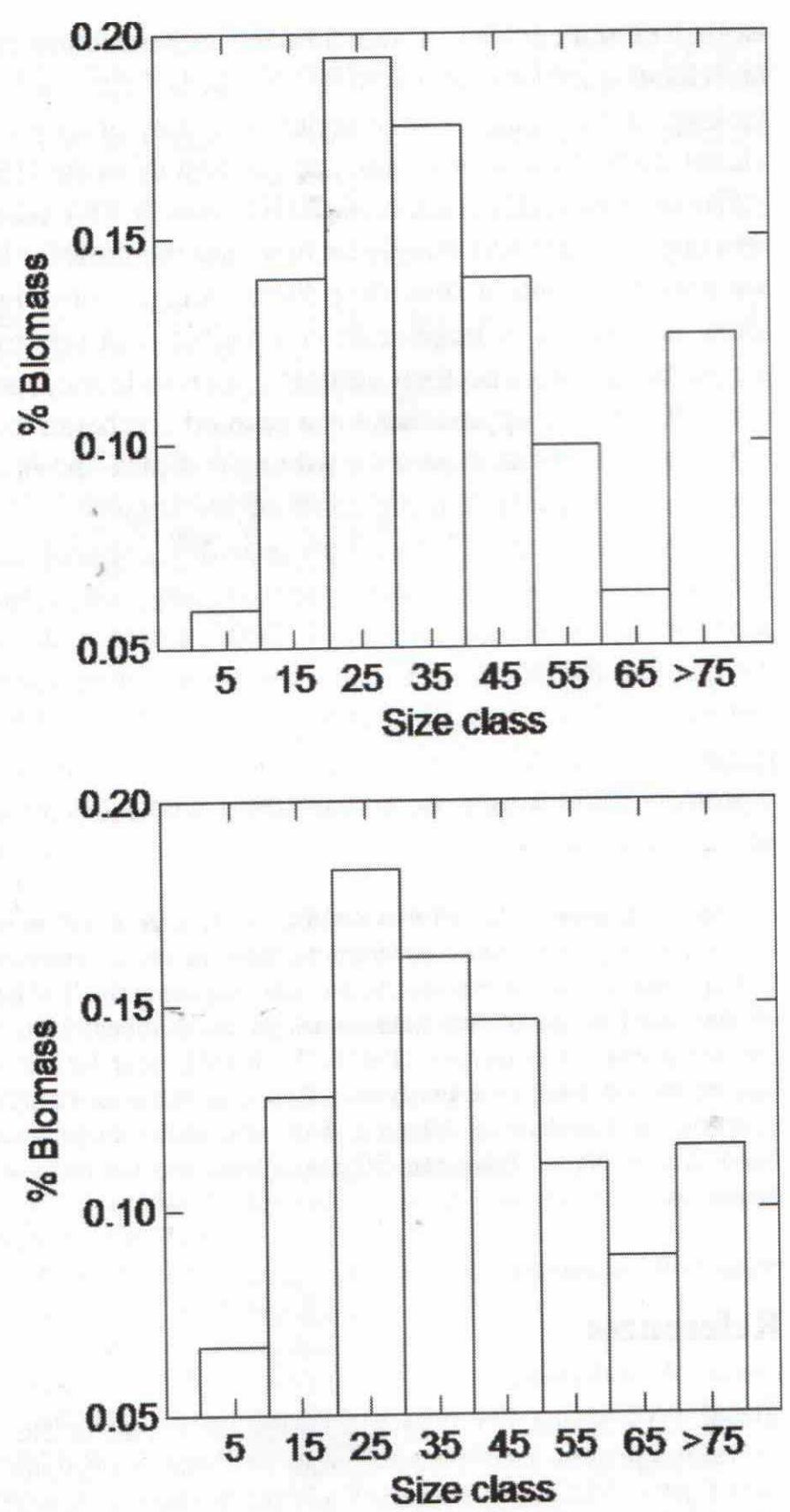

\subsection{Conclusion}

The RAPELD LTER system is unashamedly standardized. It is also unashamedly flexible. No system can guarantee answers to all questions on all scales. However, systems should be designed to be used for a wide range of questions across a great 
variety of scales. Use of standardized infrastructure cannot replace thinking about individual questions, and RAPELD was not designed for blind application, though looking at the available time series data may greatly facilitate planning for an individual study. New approaches, such as NEON in the USA (http://www.neoninc.org/), ATBI in Europe (Eymann et al. 2010), and TERN-ACEAS in Australia (http://www. tern.org.au/), are increasingly recognizing the need for LTER systems. More broadly, we now have online sites (http://www.kaggle,com/, https://kepler-project.org/) that allow custodians of large-scale compatible data sets to interface with data analysts across the globe, who then compete to provide the best analysis or model from the data. While such approaches once seemed anathema to traditional scientific process, they appear to be necessary for solving complex and multifaceted scientific questions that seemed intractable using conventional studies.

A well-planned LTER system provides a shared scientific infrastructure for all sorts of biodiversity and ecosystem studies, and infrastructure for individual projects within it (Magnusson et al. 2005; Costa and Magnusson 2010; Hero et al. 2010). The RAPELD LTER system allows integration of a diverse range of individual LTER projects using comparable methods. While its design supports LTER projects and publications using conventional scientific research approaches, the system is increasingly demonstrating its capacity to detect and inform managers about black swans.

Acknowledgments The PPBio RAPELD system in Brazil is funded by the Ministry of Science and Technology and many different partners in each Regional Hub (see http://ppbio.inpa.gov. $\mathrm{br} / \mathrm{Eng} / \mathrm{nregionais} /$ ). It has received much support from ICMBIO and IBAMA staff, and much of the coordination is undertaken through the National Institute for Science and Technology for Amazonian Biodiversity (INCT-CENBAM). The PPBio system in Australia is partially funded by the Terrestrial Ecosystem Research Network (TERN), Brisbane City Council, SEQ Catchments, Condamine Alliance, Save the Bilby Fund and Griffith University. We thank Sarah Butler, Naomi Edwards, Clay Simpkins, and the many volunteers who measured trees at Karawatha.

\section{References}

Abbott I, Le Maitre D (2010) Monitoring the impact of climate change on biodiversity: the challenge of megadiverse Mediterranean climate ecosystems. Austral Ecol 35:406-422

Adis J (ed) (2002) Amazonian arachnida and myriapoda. Pensoft, Sofia

Braga-Neto R, Luizão R, Magnusson WE, Zuquim G, Castilho CV (2008) Leaf litter fungi in a central Amazonian forest: the influence of rainfall, soil and topography on the distribution of fruiting bodies. Biodivers Conserv 17:270-2712

Buckland ST, Magurran AE, Green RE, Fewster RM (2005) Monitoring change in biodiversity through composite indices: Philos Trans R Soc B 360:245-254

Bueno AS, Bruno RS, Pimentel TP, Sanaiotti TM, Magnusson WE (2012) The width of the riparian habitats for understory birds in an Amazonian forest. Ecol Appl 22(2):722-734

Butler S (2007) Associations of mesoscale vegetation patterns with soil, topography and fire history of Karawatha. Hon Thesis, Griffith University, Gold Coast

Calzada J, Delibes M, Keller C, Palomares F, Magnusson WE (2008) First record of the bushy-tailed opossum, Glironia venusta, thomas 1912 (Didelphimorphia) from Manaus, Amazonas, Brasil. Acta Amaz 38:807-810 
Castilho CV, Magnusson WE, Araújo RNO, Luizão RCC, Luizão FJ, Lima AP, Higuchi N (2006) Variation in aboveground tree live biomass in a central Amazonian forest: effects of soil and topography. For Ecol Manage 42:95-103

Castilho CV, Magnusson WE, Araújo RNO, Luizão F (2010) Short-term temporal changes in tree live biomass in a central Amazonian Forest, Brazil. Biotropica 42:95-103

Cintra R (2008) Aves. In: Oliveira ML, Bacarro FB, Braga-Neto R, Magnusson WE (eds) Reserva ducke: a biodiversidade amazônica através de uma grade. Attema Design Editorial, Manaus, pp 77-85

Condrati LH (2009) Distribuição de espécies de anuros em zonas riparias. Masters Thesis, Instituto Nacional de Pesquisas da Amazônia, Manaus

Costa FRC, Magnusson WE (2010) The need for large-scale, integrated studies of biodiversitythe experience of the program for biodiversity research in Amazônia. Nat Cons 8:1-5

Costa FRC, Magnusson WE, Luizão RC (2005) Mesoscale distribution patterns of Amazonian understory herbs in relation to topography, soil and watersheds. J Ecol 93:863-878

Costa FRC, Castilho CV, Drucker DP, Kinupp V, Nogueira A (2008) Flora. In: Oliveira ML, Bacarro FB, Braga-Neto R, Magnusson WE (eds) Reserva ducke: a biodiversidade amazônica através de uma grade. Attema Design Editorial, Manaus, pp 21-30

Costa FRC, Guillaumet J-L, Lima A, Pereira OS (2009) Gradients within gradients: the mesoscale distribution patterns of palms in a central Amazonian forest. J Veg Sci 20:1-10

Dias MS, Magnusson WE, Zuanon J (2010) Reduced-impact logging has subtle medium-term effects on fish assemblages in central Amazonia. Cons Biol 24:278-286

Doak DF, Estes JA, Halpern BS, Jacob U, Lindberg DR, Lovvorn J, Monson DH, Tinker MT, Williams YM, Wootton JT, Carroll I, Emmerson M, Micheli F, Novak M (2008) Understanding and predicting ecological dynamics: are major surprises inevitable? Ecology 89:952-961

Drucker D, Costa FRC, Magnusson WE (2008) How wide is the riparian zone of small streams in tropical forests? a test with terrestrial herbs. J Trop Ecol 24:65-74

Espírito-Santo HMV, Magnusson WE, Zuanon J, Mendonça F, Landeiro VL (2009) Seasonal variation in fish assemblage composition of small Amazonian forest streams: evidence for predictable changes. Freshw Biol 54:536-548

Eymann J, Degreef J, Häuser C, Monje JC, Samyn Y, VandenSpiegel D (eds) (2010) Manual on field recording techniques and protocols for all taxa biodiversity inventories (ATBIs). Abctaxa 8(1, 2). http://www.abctaxa.be/volumes/volume-8-manual-atbi

Ferraz G, Marinelli CE, Lovejoy TE (2008) Biological monitoring in the Amazon: recent progress and future needs. Biotropica 40:7-10

Field SA, Tyre AJ, Possingham HP (2005) Optimizing allocation of monitoring effort under economic and observational constraints. J Wildl Manag 69:473-482

Gardner T (2010) Monitoring forest biodiversity. Earthscan, London

Goralewski KBN (2008) A influência do delineamento amostral nas estimativas de riqueza e composição de espécies de anfíbios nas margens do alto rio madeira (Rondônia, Brasil). Masters Thesis, Instituto Nacional de Pesquisas da Amazônia, Manaus

Haughland DL, Hero J-M, Schieck J, Castley JG, Boutin S, Sólymos P, Lawson BE, Holloway G, Magnusson WE (2010) Planning forwards: biodiversity research and monitoring systems for better management. Trends Ecol Evol 1210:199-200

Hero J-M, Magnusson WE, Rocha CFD, Catterall CP (2001) Antipredator defenses influence the distribution of amphibian prey species in the central Amazon forest. Biotropica 33:131-141

Hero J-M, Castley JG, Malone M,'Lawson B, Magnusson WE (2010) Long-term ecological research in Australia: innovative approaches for future benefits. Aust Zool 35:216-228

Kinupp VF, Magnusson WE (2005) Spatial patterns in the understorey shrub genus Psychotria in central Amazonia: effects of distance and topography. J Trop Ecol 21:1-12

Lefsky MA, Cohen WB, Harding DJ, Parker GG, Acker SA, Gower T (2002) LIDAR remote sensing of above-ground biomass in tree biomes. Glob Ecol Biogeogr 11:393-399

Lindenmayer DB, Likens GE (2009) Adaptive monitoring: a new paradigm for long-term research and monitoring. Trends Ecol Evol 5:482-486 
Magnusson WE, Lima AP, Hero J-M, Araújo MC (1999) The rise and fall of Hyla boans: reproduction in a neotropical gladiator frog. J Herptol 33:647-656

Magnusson WE, Lima AP, Luizão R, Luizão F, Costa FRC, Castilho CV, Kinupp VF (2005) RAPELD: A modification of the gentry method for biodiversity surveys in long-term ecological research sites. Biota Neotrop 2:1-6

Magnusson WE, Costa F, Lima A, Baccaro F, Braga-Neto R, Romero RL, Menin M, Penha J, Hero J-M, Lawson BE (2008) A program for monitoring biological diversity in the Amazon: an alternative perspective to threat-based monitoring. Biotropica 40:409-411

Mendes Pontes AR, Sanaiotti T, Magnusson WE (2008) Mamíferos de grande porte. In: Oliveira ML, Bacarro FB, Braga-Neto R, Magnusson WE (eds) Reserva Ducke: a biodiversidade amazônica através de uma grade. Attema Design Editorial, Manaus, pp 51-56

Mendes Pontes ART, Paula MD, Magnusson WE (2012) Low primate diversity and abundance in northern Amazonia and its implications for conservation. Biotropica 44(6):834-839

Mendonça FP, Magnusson WE, Zuanon J (2005) Relationships between habitat characteristics and fish assemblages in small streams of central Amazonia. Copeia 4:750-763

Mendonça F, Pazin V, Espírito-Santo H, Zuanon J, Magnusson WE (2008) Peixes. In: Oliveira ML, Bacarro FB, Braga-Neto R, Magnusson WE (eds) Reserva ducke: a biodiversidade amazônica através de uma grade. Attema Design Editorial, Manaus, pp 63-75

Menin M, Lima AP, Magnusson WE, Waldez F (2007) Topographic and edaphic effects on the distribution of terrestrially reproducing anurans in central Amazonia: mesoscale spatial patterns. J Trop Ecol 23:539-547

Menin M, Waldez F, Lima AP (2008a) Temporal variation in the abundance and number of species of frogs in 10,000 ha of a forest in central Amazonia, Brazil. South Am J Herpetol 3:68-81

Menin M, Lima AP, Rodrigues D, Waldez F (2008b) Sapos. In: Oliveira ML, Bacarro FB, Braga-Neto R, Magnusson WE (eds) Reserva ducke: a biodiversidade amazônica através de uma grade. Attema Design Editorial, Manaus, pp 21-30

Oliveira PY, Pereira de Souza JL, Baccaro FB, Franklin E (2009) Ant species distribution along a topographic gradient in a "terra-firme" forest reserve in central Amazonia. Pesq Agropec Bras 44:852-860

Parr TW, Ferretti M, Simpson IC, Forsius M, Kovács-Láng E (2002) Towards a long-term integrated monitoring programme in Europe: network design in theory and practice. Env Monit Assess 78:253-290

Pazin VF, Magnusson WE, Zuanon J, Mendonça FP (2006) Fish assemblages in temporary ponds adjacent to 'terra-firme' streams in central Amazônia. Freshw Biol 51:1025-1037

Pitman NCA, Widmer J, Jenkins CN, Stocks G, Seales L, Paniagua F, Bruna EM (2011) Volume and geographical distribution of ecological research in the andes and the Amazon, 1995-2008. Trop Cons Sci 4:64-81

Ribeiro JELS, Hopkins MJG, Vincentini A, Sothers CA, Costa MAS, Brito JM, Souza MAD, Martins LHP, Lohmann LG, Assunção PACL, Pereira EC, Silva CF, Mesquita MR, Procópio LC (1999) Flora da reserva ducke. INPA-DFID, Manaus, AM

Rodrigues DJ, Lima AP, Magnusson WE, Costa FRC (2010) Temporary pond availability and tadpole species composition in central Amazonia. Herpetologica 66:113-119

Schietti J, Drucker D, Keizer E, Carneiro-Filho A, Magnusson W (2007) Avaliação do uso de dados SRTM para estudos ecológicos na Amazônia central. Anais Online do XIII Simpósio Brasileiro de Sensoriamento Remoto (XIII SBSR), INPE, São José dos Campos, SP

Taleb NN (2007) The black swan. Penguin Books, New York

Toledo JJ, Magnusson WE, Castilho CV (2009) Influence of soil, topography and substrates on differences in wood decomposition between one-hectare plots in lowland tropical moist forest in central Amazonia. J Trop Ecol 25:649-656

Toledo JJ, Magnusson WE, Castilho CV, Nascimento HEM (2011) How much variation in tree mortality is predicted by soil and topography in central Amazonia? For Ecol Manag 262:331-338 
Toledo JJ, Magnusson WE, Castilho CV, Nascimento HEM (2012) Tree mode of death in central Amazonia: effects of soil and topography on tree mortality associated with storm disturbances. For Ecol Manag 263:253-261

Westoby M (1991) On long-term ecological research in Australia. In: Risser PG (ed) Long-term ecological research. Wiley, New York, pp 191-209

Wintle BA, Runge MC, Bekessy SA (2010) Allocating monitoring effort in the face of unknown unknowns. Ecol Lett 13:1325-1337 